9 AIMS Trial Study Group. Effect of intravenous APSAC on mortality after acute myocardial infarction: preliminary report of a placebo controlled clinical trial. Lancet 1990;335:545-9.

10 AIMS Trial Study Group. Long-term effects of intravenous anistreplase in acute myocardial infarction: final report of the AIMS study. Lancet 1990;335:427-31

11 Simoons ML, Serruys PW, Brand M, Bars F, De Zwaans C, Res J, et al. Improved survival after early thrombolysis in acute myocardial infarction. Lancet 1985;ii:578-82.

12 Williams DO, Borer J, Braunwauld E, Chesebro JH, Cohen LS, Dalen J, et al. Intravenous recombinant tissue-type plasminogen activator in patients with acute myocardin inforction: a myocardial infarction trial. Circulation 1986;73:338-46.

13 Harrison DG, Ferguson DW, Collins SM, Skorton DJ, Eriksen EE, Kiosho $\mathrm{JM}$, et al. Rethrombosis after reperfusion with streptokinase: importance of JM, et al. Rethrombosis after reperfusion with strepto

14 Ellis SG, Topol EJ, George BS, Kereiakes DJ, Debowey D, Sigmon KN et al. Recurrent ischaemia without warning. Analysis of risk factors for in hospital ischaemic events following successful thrombolysis with intravenous tissue plasminogen activator. Circulation 1989;80:1159-65.

15 Yusuf S, Peto R, Lewis J, Collins R, Sleight P. Beta blockade during and after myocardial infarction: an overview of the randomised trials. Prog Cardiovasc Dis 1985;27:335-71.

16 Wolffenbuttel BHR, Verdouw PD, Scheffer MG, Bom HPA, Bijleveld RE Hugenholtz PG. Significance of haemodynamic variables in coronary care unit for prediction of survival after acute myocardial infarction. $\mathrm{Br}$ Hear $f$ 1983;50:266-72.

17 Deckers JW, Fioretti P, Brower RW, Baarman T, Beelen A, Simoons ML. Prediction of 1 year outcome after complicated and uncomplicated myocardial infarction: Bayesian analysis of predischarge exercise test results in 300 patients. Am Hear f 1987;113:90-8.

18 Krone RJ, Friedman E, Thanavaro S, Miller JP, Kleiger RE, Oliver GC Long term prognosis after first $Q$ wave (transmural) or non- $Q$ wave (nontransmural) myocardial infarction: analysis of 593 patients. $A m \mathcal{F}$ Cardiol 1983;52:234-9.

9 Frabicius-Bjerre N, Munkvad M, Knudsen JB. Subendocardial and transmural myocardial infarction. A five year study. Am $\mathcal{F}$ Med 1979;66:986-93.

20 Murray DP, Salih M, Tan LB, Murray RG, Littler WA. Prognostic stratification of patients after myocardial infarction. Br Heart $\mathcal{f} 1987 ; 57$ : 313-8.

21 Cleempoel H, Vainsel H, Dramaix M, Lenaers A, Contu E, Hoylaerts M, et al. Limitations on the prognostic value of predischarge data after myocardial infarction. Br Heart $\mathcal{f} 1988 ; 60: 98-103$.

22 Henning H, Gilpin EA, Covell W, Swan EA, O'Rourke RA, Ross J. Prognosis after acute myocardial infarction: a multivariate analysis of mortality and survival. Circulation 1979;59:1124-30.

23 Dubois C, Pierard LA, Albert A, Smeets J-P, Demoulin J-C, Boland J, et al. Short term risk stratification at admission based on simple clinical data in acute myocardial infarction. Am $f$ Cardiol 1988;61:216-9.

24 Sanz G, Castaner A, Betrui A, Magrina J, Roig E, Coll S, et al. Determinants of prognosis in survivors of myocardial infarction. A prospective clinical angiographic study. $N$ Engl f Med 1982;306:1065-70.

25 Norris RM, Barnaby PF, Brandt PWT, Geary GG, Whitlock RML, Wild CJ, et al. Prognosis after recovery from first acute myocardial infarction: determinants of reinfarction and sudden death. Am 7 Cardiol 1984;53. $408-13$.

26 Gomez-Marin O, Folsom AR, Kottke TE, Shu-Chen H, Jacobs DR, Gillum $\mathrm{RF}$, et al. Improvement in long term survival among patients hospitalised with acute myocardial infarction, 1970 to 1980 . The Minnesota Heart Survey. NEngl F Med 1987;316:1353-9.

27 Martin CA, Thompson PL, Armstrong BK, Hobbs MST, de Klerk N. Long term prognosis after recovery from myocardial infarction: a nine year followup of the Perth Coronary Register. Circulation 1983;68:961-9.

28 Pohjola S, Siltanen P, Romo M. Five year survival of 728 patients after myocardial infarction. A community study. Br Heart f 1980;43:176-83.

29 Mueller HS, Cohen LS, Braunwald E, Formen S, Feit F, Ross A, et al Predictors of early morbidity and mortality after thrombolytic therapy of acute myocardial infarction. Analysis of patient subgroups in the thrombolysis in myocardial infarction (TIMI) trial, phase II. Circulation 1992;85: 1254-64.

30 Simoons ML, Vos J, Tijssen JGP, Vermeer F, Verheugt FWA, Krauss $H$, et al. Long term benefit of early thrombolytic therapy in patients with acute myocardial infarction: 5 year follow-up of a trial conducted by the Interuniversity Cardiology Institute of the Netherlands. $f \mathrm{Am}$ Coll Cardiol 1989;14:1609-15.

31 White HD, Norris RM, Brown MA, Brandt PWT, Whitlock RML, Wild CJ. End-systolic volume as the major determinant of survival after recovery from myocardial infarction. Circulation 1987;76:44-51.

32 Barbash GI, White HD, Modan M, Van der Werf F. Significance of smoking in patients receiving thrombolytic therapy for acute myocardial infarction. Experience gleaned from the international tissue plasminogen activato streptokinase mortality trial. $7 \mathrm{Am}$ Coll Cardiol 1992;20:36-41.

33 Rivers JT, White HD, Cross DB, Williams BF, Norris RM. Reinfarction after thrombolytic therapy for acute myocardial infarction followed by conservative management: incidence and effect of smoking. $7 \mathrm{Am}$ Coll Cardiol 1990;16:340-8.

(Accepted 3 fune 1993)

\title{
National Health Service breast screening programme results for 1991-2
}

\author{
J Chamberlain, S M Moss, A E Kirkpatrick, M Michell, L Johns
}

Cancer Screening

Evaluation Unit, Institute of Cancer Research, Sutton, Surrey SM2 5NG

J Chamberlain,

epidemiologist

S M Moss, statistician

L Johns, higher computer officer

South East Scotland Breast Screening Programme, Ardmillan Terrace, Edinburgh EH11 2JL

A E Kirkpatrick, radiologist

Breast Screening Unit, King's College Hospital, London SE5 9RS

M Michell, radiologist

Correspondence to:

Dr Kirkpatrick.

$B M \mathcal{F} 1993 ; 307: 353-6$

\section{Abstract}

Objectives-To report the results of the NHS breast screening programme for the year March 1991 to April 1992.

Design-A report of statistics was derived from Körner (K62) returns and from the radiology quality assurance programme.

Main outcome measures-Detection rates for breast cancer and small ( $\leqslant 10 \mathrm{~mm}$ diameter) invasive cancer, benign biopsy rates, and recall and acceptance rates.

Results-The acceptance rate for screening across the United Kingdom was $71 \cdot 3 \%$. The referral rate for further investigation was $6 \cdot 2 \%$ (regional $4 \cdot 3-9 \cdot 0 \%$ ). The breast cancer detection rate was $6 \cdot 2$ cancers per 1000 women screened $(5 \cdot 1-9 \cdot 0)$ and the detection rate of invasive cancers $\leqslant 10 \mathrm{~mm}$ was $1 \cdot 4 / 1000$ $(1 \cdot 0-2 \cdot 3) .72 \%$ of screening programmes reached the target $70 \%$ acceptance rate, and $95 \%$ of programmes achieved a recall rate of less than $10 \% .75 \%$ of programmes had a cancer detection rate of more than $5 / 1000$, but only $32 \%$ had a detection rate for invasive cancers $\leqslant 10 \mathrm{~mm}$ of more than $1 \cdot 5 / 1000$.

Conclusions-Overall, the results of the screening programme for the year 1991-2 can be regarded as extremely satisfactory, given the size and complexity of the operation.

\section{Introduction}

After the publication of the Forrest report in $1987^{1}$ a structured breast screening programme for women aged 50 and over was introduced into the National
Health Service. All women aged 50-64 who are registered with general practitioners are invited to be screened by mammography every three years, and asymptomatic women aged over 64 may obtain three yearly screening on demand. By the end of March 1991, 82 separate screening programmes were in operation, and another eight began screening during the next 10 months. These 90 programmes are sufficient to cover the 4.5 million women aged $50-64$ in the United Kingdom once every three years and allow for about $10 \%$ of screening examinations to be self referrals of older women. As each round of screening is planned to extend over three years, only a minority of programmes-those starting in 1988-had completed their first round of invitations by the end of March 1992. The period covered by this report is the year from 1 April 1991 to 31 March 1992, so that all but eight programmes contributed a full year's data; only three contributed less than nine months' information.

\section{Methods}

One aspect of the national quality control of the screening programme is a standardised record system which permits the service to be routinely monitored. A number of different computerised record systems (five in total) have been specifically designed for the NHS breast screening programme, and tables showing various aspects of the performance of the screening service can be produced from these. Each screening programme in England is required to produce a "Körner" statistical return on form $\mathrm{KC} 62$ for the Department of Health each year, and similar arrange- 
ments apply in Scotland, Wales, and Northern Ireland. Working through regional coordinators in England, and national coordinators for the three Celtic countries, the cancer screening evaluation unit in the Institute of Cancer Research collects all these statistical returns. They are then entered into the unit's computer before analysis.

Some subdivisions of the data are not possible for the present report but will be in future. These include a breakdown of women invited into those being invited for their first screen and those being invited for routine screening after three years and, for Scotland, breakdowns by age group and by type of screen.

A few programmes experienced problems and long delays in obtaining completed forms for computer entry about women who had been referred to hospital for biopsy or treatment of breast cancer, or both. This means that there were several screening episodes in these programmes for which the outcome was still unrecorded at the time the Körner statistical returns were compiled. In almost all these cases the radiologists directing the screening programme learnt of the final diagnosis from their surgical and pathology colleagues, even though the detailed computer forms had not yet been completed. Therefore in this report the statistical returns for these programmes have been supplemented with data on referrals, biopsies, and cancers, collected to assist in radiological quality control by the "radiology big 18." This is a group of radiologists with responsibility for quality assurance in each of the 14 English regions, Scotland, Wales, Northern Ireland, and the private sector, totalling 18 in all. The radiologists' supplementary data provided more complete information on outcome for women screened between 1 April 1991 and 31 March 1992, the period covered by the KC62 returns. Unfortunately the supplementary data are available only at regional level, not individual screening programme level. Data for calculating the number of screening programmes meeting specific performance targets therefore come only from the KC62 returns and may thus lead to a slight overestimate of the number of programmes with satisfactorily low referral rates and biopsy rates and to a slight underestimate of the number with a satisfactorily higher cancer detection rate.

\section{Results}

UPTAKE OF SCREENING

In $1991-2,71 \cdot 3 \%$ of the 1443914 women who were invited for screening accepted the invitation (table I). There was a slight fall in response with increasing age. It is thought that the 40989 women aged over 65 who were invited were selected as eligible when they were still 64 . In addition to the women screened in response to invitation, a further 30719 referred themselves to the screening clinics (table II).

\section{REFERRAL FOR ASSESSMENT}

Because of the potential for distress in women referred for diagnostic assessment as a result of a suspicious screening mammogram, all NHS screening programmes provide a dedicated assessment clinic where such women can be speedily and compassionately

TABLE I-Acceptance of invitations to screening (first and second rounds combined)

\begin{tabular}{lcrcc}
\hline & $\begin{array}{c}\text { No of women } \\
\text { invited }\end{array}$ & $\begin{array}{c}\text { No } \\
\text { screened }\end{array}$ & \% Response & $\begin{array}{c}\text { Regional range of } \\
\text { response rates (\%) }\end{array}$ \\
\hline England, Wales, Northern Ireland: & & & & \\
$\quad 50-54$ & 422635 & 304002 & 71.93 & $56 \cdot 84-79 \cdot 40$ \\
$\quad 55-59$ & 435593 & 316338 & $72 \cdot 62$ & $59 \cdot 02-83 \cdot 66$ \\
$\quad 60-64$ & 417830 & 290584 & $69 \cdot 55$ & $58 \cdot 07-82 \cdot 89$ \\
$\geqslant 65$ & 40989 & 27032 & 65.95 & $46 \cdot 53-97 \cdot 05$ \\
Scotland (all ages) & 126867 & 91028 & $71 \cdot 75$ & $63 \cdot 93-82 \cdot 82$ \\
United Kingdom (all ages) & 1443914 & 1028984 & $51 \cdot 26$ & $57 \cdot 88-81 \cdot 51$ \\
\hline
\end{tabular}

TABLE II-Referral rates from screening

\begin{tabular}{lrrr}
\hline Type of screen & $\begin{array}{c}\text { No of } \\
\text { women } \\
\text { screened }\end{array}$ & $\begin{array}{c}\text { No (\%) } \\
\text { referred }\end{array}$ & $\begin{array}{c}\text { Regional } \\
\text { range of } \\
\text { refral rates } \\
(\%)\end{array}$ \\
\hline England, Wales, Northern Ireland: & & & \\
$\quad$ First & 867440 & $55330(6 \cdot 38)$ & $4 \cdot 64-9 \cdot 05$ \\
$\begin{array}{l}\text { Routine rescreen } \\
\text { Referred by self or GP }\end{array}$ & 70516 & $2111(2 \cdot 99)$ & $0 \cdot 89-14 \cdot 21$ \\
Scotland (all types) & 30719 & $1946(6 \cdot 33)$ & $2 \cdot 47-12 \cdot 94$ \\
\hline Total & 91028 & $6667(7 \cdot 32)$ & \\
\hline & 1059703 & $66054(6.23)$ & $4 \cdot 33-9 \cdot 04$ \\
\hline
\end{tabular}

TABLE III-Breast biopsies resulting from screening

\begin{tabular}{|c|c|c|c|}
\hline Type of screen & $\begin{array}{c}\text { No of } \\
\text { women } \\
\text { screened }\end{array}$ & $\begin{array}{c}\text { No of } \\
\text { biopsies (\% } \\
\text { of women } \\
\text { screened) }\end{array}$ & $\begin{array}{c}\text { Regional } \\
\text { range of } \\
\text { biopsy rates } \\
\text { (\% of women } \\
\text { screened) }\end{array}$ \\
\hline \multicolumn{4}{|c|}{ England, Wales, Northern Ireland: } \\
\hline First & 867440 & $7904(0.91)$ & $0 \cdot 74-1 \cdot 40$ \\
\hline Routine rescreen & 70516 & $334(0.47)$ & $0 \cdot 13-4 \cdot 21$ \\
\hline Referred by self or GP & 30719 & $401(1 \cdot 30)$ & $0.62-3.39$ \\
\hline Scotland (all types) & 91028 & $794(0.87)$ & \\
\hline Total & 1059703 & $9433(0.89)$ & $0 \cdot 69-1 \cdot 31$ \\
\hline
\end{tabular}

investigated by an expert team consisting of a radiologist, clinician, pathologist, and nurse. Table II shows that overall 66054 women, $6 \cdot 2 \%$ of those screened, were referred in 1991-2.

\section{BIOPSIES}

Table III relates to women for whom a histological diagnosis was obtained after surgery and thus excludes those who had only fine needle aspiration cytology. A total of $9433(0.9 \%)$ of screened women had histological examination, in whom 6605 tumours were malignant and 2828 benign.

\section{BREAST CANCERS}

Overall, 6.3 breast cancers were detected per 1000 women screened in the first round and 3.4/1000 at the routine rescreen three years later (table IV). These included ductal carcinoma of the breast in addition to invasive breast cancer. Detection rates increased with increasing age and were higher in self selected women. A more important indication of screening performance is the rate at which small invasive cancers $(10 \mathrm{~mm}$ or less) were detected, shown as $1.4 / 1000$ screened in the first round (table V).

PERFORMANCE OF INDIVIDUAL SCREENING PROGRAMMES

At the start of the screening programme a number of target performance indicators for the first round of screening were suggested. ${ }^{2}$ These included an acceptance rate of $70 \%$, a referral rate of $10 \%$ or less, a biopsy rate of $3 \%$ or less with a malignant to benign ratio greater than 0.5 to 1 , a cancer detection rate in the first round of at least $5 / 1000$, and a detection rate of invasive cancers $\geqslant 10 \mathrm{~mm}$ in diameter of at least $1 \cdot 5 / 1000$.

Table VI shows that, on the basis of data from KC62 returns, $72 \%$ of programmes achieved the target uptake of $70 \%$. Ninety five per cent had a referral rate of $10 \%$ or less and all were at or below the target biopsy rate. Seventy five per cent had a cancer detection rate of at least $5 / 1000$, and only three programmes had a rate significantly lower than this at the $5 \%$ level, but only $32 \%$ met the target for the detection of small cancers. Table VII shows the number of programmes meeting different numbers of targets, separately for those programmes starting during 1987-9 and those starting in 1990-2. Fifty nine per cent of programmes met five or more of the six targets, and $93 \%$ met at least four. There was no overall difference between those programmes starting in 1989 or earlier and the rest. 
The target peformance indicators were based largely

\begin{tabular}{|c|c|c|c|c|}
\hline \multirow[b]{2}{*}{ Type of screen } & \multirow[b]{2}{*}{$\begin{array}{l}\text { No of women } \\
\text { screened }\end{array}$} & \multicolumn{2}{|c|}{ Breast cancers } & \multirow{2}{*}{$\begin{array}{c}\text { Regional range of } \\
\text { cancer detection rates } \\
\text { (per } 1000 \text { women screened) }\end{array}$} \\
\hline & & No & $\begin{array}{c}\text { No per } 1000 \\
\text { women screened }\end{array}$ & \\
\hline \multicolumn{5}{|c|}{ England, Wales, Northern Ireland: } \\
\hline First & 867440 & 5470 & $6 \cdot 3$ & $5 \cdot 1-9 \cdot 5$ \\
\hline Routine rescreen & 70516 & 242 & $3 \cdot 4$ & $1 \cdot 2-15 \cdot 8$ \\
\hline Referred by self or GP & 30719 & 315 & $10 \cdot 3$ & $5 \cdot 6-26 \cdot 2$ \\
\hline Scotland (all types) & 91028 & 578 & $6 \cdot 3$ & \\
\hline Total & 1059703 & 6605 & $6 \cdot 2$ & $5 \cdot 1-9 \cdot 0$ \\
\hline
\end{tabular}

TABLE V-Detection rates of invasive cancers $\leqslant 10 \mathrm{~mm}$ in diameter

\begin{tabular}{|c|c|c|c|c|}
\hline \multirow[b]{2}{*}{ Type of screen } & \multirow[b]{2}{*}{$\begin{array}{l}\text { No of women } \\
\text { screened }\end{array}$} & \multicolumn{2}{|c|}{ Invasive cancers $\leqslant 10 \mathrm{~mm}$} & \multirow{2}{*}{$\begin{array}{c}\text { Regional range of } \\
\text { detection rates } \\
\text { (per } 1000 \text { women screened) }\end{array}$} \\
\hline & & No & $\begin{array}{c}\text { No per } 1000 \\
\text { women screened }\end{array}$ & \\
\hline \multicolumn{5}{|c|}{ England, Wales, Northern Ireland: } \\
\hline First & 867440 & 1223 & 1.4 & $1 \cdot 0-2 \cdot 4$ \\
\hline Routine rescreen & 70516 & 51 & 0.7 & $0 \cdot 2-5 \cdot 3$ \\
\hline Referred by self or GP & 30719 & 49 & $1 \cdot 6$ & $0 \cdot 4-6 \cdot 2$ \\
\hline Scotland (all types) & 91028 & 145 & $1 \cdot 6$ & \\
\hline Total & 1059703 & 1468 & $1 \cdot 4$ & $1 \cdot 0-3 \cdot 0$ \\
\hline
\end{tabular}

TABLE VI-Screening programmes meeting targets for prevalent round ${ }^{*}$ (women aged 50-64)

No (\%) of

screening programmes

\begin{tabular}{ll}
\hline Response rate $>70 \%$ & $63(72)$ \\
Referral rate $<10 \%$ & $84(95)$ \\
Biopsy rate $<3 \%$ & $88(100)$ \\
Malignant:benign ratio $>0 \cdot 5: 1$ & $77(87)$ \\
Cancer detection ratio $\geqslant 5 / 1000$ & $66(75)$ \\
Cancers $\leqslant 10$ mm diameter $>1 \cdot 5 / 1000$ & $28(32)$
\end{tabular}

* One programme was excluded as prevalent round was nearly complete \# One programme was excluded as prevalent round was nearly complete
before 1 April 1991, and one programme was excluded owing to missed data on Körner return.

TABLE VII-Number (percentage) of screening programmes meeting targets

\begin{tabular}{lccccc}
\hline & \multicolumn{5}{c}{ No of targets met } \\
\cline { 2 - 6 } Programme start & 2 & 3 & 4 & 5 & 6 \\
\hline $1987-9(\mathrm{n}=47)$ & $1(2)$ & $\begin{array}{l}1(2) \\
4(10)\end{array}$ & $11(40)$ & $17(36)$ & $10(21)$ \\
$1990-2(\mathrm{n}=41)$ & $22(54)$ & $3(7)$ \\
\hline Total $(\mathrm{n}=88)^{\star}$ & $1(1)$ & $5(6)$ & $30(34)$ & $39(44)$ & $13(15)$
\end{tabular}

*One programme was excluded as prevalent round was nearly complete before 1 April 1991, and one programme was excluded owing to missed data on Körner return.

\section{Discussion}

During the year 1991-2 almost one and a half million women were invited for screening. This shows that the overall screening programme is now running at sufficient capacity to invite all eligible women once every three years. There is still, however, a problem in the accuracy of the family health services authorities' lists of names and addresses in many areas, particularly in London. Some of those named may no longer be resident at the listed address ("ghosts" whose presence in the denominator leads to underestimation of uptake) and, more worryingly, some women may be resident but not registered with a local general practitioner and hence will never be invited. These problems are being addressed by family health services authorities and by computerisation of the NHS central register, public education to register with general practitioners, and the new general practitioner contract.

That the data from the standard returns need to be augmented is clearly unsatisfactory. It is hoped that this can be avoided in future years by improvements in computer software and by more complete and timely data entry.

on the experience of two screening clinics in Edinburgh and Guildford that took part in the United Kingdom trial of early detection of breast cancer. ${ }^{3}$ There was some early scepticism as to whether the results obtained in these research centres could be translated into such widespread practice as now exists in the NHS breast screening programme, and it is gratifying to observe that these targets are almost all being met and in some cases exceeded. An overall acceptance of $71 \%$ is surprisingly high for British women in this age group, although the wide variation in acceptance across the country suggests that many districts need to improve their performance. A recent review of research findings in this area highlights the importance of high uptake and summarises present knowledge. ${ }^{4}$ Women's views on the screening programme are being studied in various research protocols.

In future years a breakdown of acceptance of invitations for the first screen and for subsequent routine three yearly screens will indicate whether the experience of screening is acceptable to women. Only if high participation can be maintained will the programme succeed. The relatively low referral rates and rates of benign biopsy specimens are encouraging, since the anxiety caused by false positive results of screening is often cited as the most serious side effect of screening. A further reduction in recall rates can be anticipated in future rounds of screening as a reflection of the availability of previous films with which to compare current examinations. In those centres already established on their second round of screening, recall rates of the order of $3 \%$ are currently being recorded. Interestingly, comparison of recall rates and cancer detection rates around the various regions in Britain shows no relation between recall rate and cancer detection rate. A higher recall rate might be expected to yield a higher detection rate, but this does not seem to be the case in practice. Similarly, there is no relation between the recall rate and the detection rate for small cancers. It is also desirable to minimise the number of unnecessary biopsies, and an overall biopsy rate of $0.89 \%$ with a positive predictive value for cancer of $70 \%$ means that across the United Kingdom approximately three out of four biopsies result in a diagnosis of cancer. In some of the Swedish screening programmes the positive predictive value can be as high as $86 \%,{ }^{5}$ but in many centres in the United States the figure is $10 \%$ or below. At this stage in the British programme the positive predictive value of $70 \%$ for surgical biopsy can be regarded as a very satisfactory figure.

No region or country is failing to meet the target breast cancer detection rate of $5 / 1000-73 \%$ of pro-

\section{Public health implications}

- Implementation of a national breast screening programme was recommended in 1987, and 90 separate screening programmes were in operation by 1992

- These programmes cover 4.5 million British women aged 50-64 every three years

- $71.3 \%$ of women accepted screening during the year March 1991 to April 1992, and 6.2\% were referred for further investigation; 6.2 cancers were detected per 1000 women screened - $72 \%$ of screening programmes reached the target $70 \%$ acceptance rate and $95 \%$ achieved a recall rate of less than $10 \%$

- Given the size and complexity of the system, these results are extremely satisfactory 
grammes are meeting this target. The number failing to do so is little more than expected from chance variation, and many regions now exceed it, which has led to adoption of a new "achievable" standard of $6 / 1000$. However, only six of the 17 regions and countries and $32 \%$ of individual programmes reached the target of at least 1.5 small breast cancers (diameter $\leqslant 10 \mathrm{~mm}$ ) per 1000 screened. This criterion is used both as an indicator of the quality of mammography and as an indicator of the long term change in prognosis which, it is hoped, will be achieved by screening. More experience is needed to assess whether the detection rate of 3.4 breast cancers per 1000 at the three yearly repeat screen is sufficient to keep down the rate of interval cancers to $25 \%$ or less of expected three yearly incidence. ${ }^{6}$ All programmes are now setting up mechanisms for the routine reporting of interval cancers and cancers in non-responding eligible women from regional cancer registries and in some cases pathology laboratories. These will enable longer term predictions of whether the national screening programme is on course to meet its Health of the Nation target of a $25 \%$ reduction of breast cancer mortality in eligible women by the year $2000 .^{7}$

We are grateful to the administrative staff in the numerous screening offices who ran the original tables for their patience in responding to our numerous queries; to the radiologists who provided data for "the big 18"; to the regional and national coordinators who helped us to chase up missing data; to Professor Martin Vessey, chairman of the Department of Health's Advisory Committee on Breast Cancer Screening, and Mrs Julietta Patnick, National Coordinator of NHS breast screening programme for their encouragement; and to Mr Richard Yates of Department of Health's Statistics Division. The Cancer Screening Evaluation Unit at the Institute of Cancer Research is supported by the Department of Health Research and Development Section.

1 Forrest APM. Breast cancer screening: repont to the health ministers of England, Wales, Scotland, and Northern Ireland. London: HMSO, 1986.

2 Department of Health. Guidelines on the establishment of a quality assurance system for the radiological aspects of mammography used in breast screening. Sheffield: NHSBSP Publications, Trent Regional Health Authority, 1988

3 UK Trial of Early Detection of Breast Cancer Group. Breast cancer mortality after ten years in the UK trial of early detection of breast cancer. The Breast 1993;2:13-20.

4 Report of the UKCCCRNHSBSP workshop on acceptability research. Sheffield: NHSBSP (in press)

5 Frisell J, Eklund G, Hellstrom L, Lidbrink E, Rutqvist L-E, Somell A Randomized study of mammography - preliminary report of mortality in the Stockholm trial. Breast Cancer Research and Treatment 1991;18:49-56.

6 Tabar L, Fagerberg G, Day NE, Holmberg L. What is the optimum interval between mammographic screening examinations? Br $f$ Cancer 1987;55: between

7 Secretary of State for Health. The Health of the Nation. A strategy for health in England. London: HMSO, 1992

(Accepted 25 fune 1993)

\title{
Prostitution and risk of HIV: female prostitutes in London
}

\author{
Helen Ward, Sophie Day, Jane Mezzone, Lucinda Dunlop, Catrina Donegan, Sara Farrar, \\ Luke Whitaker, John R W Harris, David L Miller
}

Abstract

Objective-To measure the prevalence of HIV and to describe established risk factors in female prostitutes.

Design-A cross sectional survey.

Setting-A genitourinary medicine clinic, streets, and magistrates' courts in London.

Subjects-280 female prostitutes recruited between April 1989 and August 1991.

Main outcome measures-Infection with HIV-1, reported risk behaviours, and prevalence of sexually transmitted infections.

Results-228 of the women had HIV tests, and two $(0.9 \%(95 \%$ confidence interval $0 \%$ to $2 \cdot 1 \%))$ were infected with HIV-1. Reported use of condoms was high for commercial clients and low for non-paying partners: $98 \%(251 / 255)$ of women used condoms with all clients and $12 \%(25 / 207)$ with non-paying partners for vaginal intercourse. Twenty two women were current or past injecting drug users. Of the 193 women examined for sexually transmitted infections, 27 had an acute infection (gonorrhoea, chlamydia, trichomonas, or primary genital herpes) at the time of interview. Infection was associated with younger age and increasing numbers of non-paying sexual partners, but not with duration of prostitution, numbers of clients, or reports of condom failures. When age and numbers of non-paying partners were analysed by logistic regression they remained significantly associated with sexually transmitted infections.

Conclusions-A large and diverse sample of prostitutes had a low prevalence of infection with HIV and high levels of use of condoms in commercial sex. There was a significant risk of other sexually transmitted infections associated with prostitutes' non-commercial sexual relationships, in which unprotected sex is common. Interventions to reduce the risk of sexually transmitted infections in prosti- tutes should address both commercial and noncommercial sexual partnerships.

\section{Introduction}

It is unclear whether prostitute women in Europe are at risk of heterosexually acquired HIV independently of use of injected drugs. The risk of HIV infection has been highest in those who have a history of use of injected drugs which is associated with a history of street prostitution. ${ }^{1-3}$

A prevalence of infection with HIV-1 of $1.6 \%$ was reported in 188 female prostitutes studied during $1986-8$ in a London genitourinary medicine clinic. ${ }^{4}$ The work reported here was designed to show whether this low prevalence was related to the stage of the epidemic, sampling bias, or effective risk avoidance through the use of condoms.

\section{Subjects and methods}

A representative sample of prostitutes is difficult to define, but we had previously described the major sectors of prostitution in London ${ }^{5}$ and we developed methods of recruitment to ensure that our sample included women working in all these sectors. Between April 1989 and August 1991 prostitutes were recruited by referral from health workers in the genitourinary medicine clinic at St Mary's Hospital, referral from friends and colleagues of prostitutes, fieldwork (visiting streets, magistrates' courts, flats, agencies, and saunas), and telephone. We aimed for a sample size of at least 200 women to detect a prevalence as low as $2 \%$ with a $95 \%$ confidence interval that did not include zero.

A questionnaire asking for information on medical, social, and prostitution history was administered by trained interviewers. All participants were offered a HIV test, although acceptance was not a condition for 